\title{
Rembrandt's An Old Man in Military Costume: the underlying image re-examined
}

\author{
Karen Trentelman ${ }^{1} \cdot$ Koen Janssens ${ }^{2} \cdot$ Geert van der Snickt $^{2}$ • \\ Yvonne Szafran ${ }^{3} \cdot$ Anne T. Woollett $^{3} \cdot$ Joris Dik $^{4}$
}

Received: 16 April 2015/Accepted: 6 July 2015/Published online: 1 September 2015

(c) The Author(s) 2015. This article is published with open access at Springerlink.com

\begin{abstract}
The painting An Old Man in Military Costume in the J. Paul Getty Museum, by Rembrandt Harmensz van Rijn, was studied using two complementary, elementspecific imaging techniques-neutron activation autoradiography (NAAR) and macro-X-ray fluorescence (MAXRF) mapping - to reveal the second, hidden painting. NAAR provided a strong image of the face and cloak of the underlying figure, along with an indication of the chemical composition. The single-element distribution maps produced by MA-XRF mapping provided additional details into the shape of the underlying image and the composition of the pigments used. The underlying figure's face is richer in mercury, indicative of the pigment vermilion, than the face of the figure on the surface. Likewise, the cloak of the underlying figure is richer in copper than the surface figure though the identity of the copper-containing pigment cannot be determined from these data. The use of iron earth pigments, specifically Si-rich umbers, is indicated through the complementary information provided by the NAAR and MA-XRF maps. These data are used to create a false
\end{abstract}

Joris Dik

j.dik@tudelft.nl

Karen Trentelman

k.trentelman@getty.edu

1 Getty Conservation Institute, 1200 Getty Center Drive, Suite 700, Los Angeles, CA 90049, USA

2 X-ray Analysis, Electrochemistry and Speciation, University of Antwerp, Groenenborgerlaan 171, 2020 Antwerp, Belgium

3 J. Paul Getty Museum, 1200 Getty Center Drive, Suite 400, Los Angeles, CA 90049, USA

4 Laboratory of Materials Science, Delft University of Technology, Mekelweg 2, 2628 CD Delft, The Netherlands color digital reconstruction, yielding the most detailed representation of the underlying painting to date.

\section{Introduction}

Hidden paintings-paintings that have been painted over, either by the original artist or in subsequent interventionshave long been of interest to scholars because of their potential to reveal information about the working practice of an artist or workshop. In order to reveal the first composition without destroying or disturbing what had been painted over it, the cultural heritage community has long looked to emerging scientific methods. As technological advances allow the underlying painting to be imaged with increasing clarity and scientific detail, the hidden painting may be revealed in stages, sometimes over the course of decades. In this paper, we present the most recent efforts carried out to reveal the figure concealed beneath the J. Paul Getty Museum's An Old Man in Military Costume by Rembrandt Harmensz van Rijn (JPGM 78.PB.246, 1630-31; Fig. 1a) using macro-X-ray fluorescence (MA$\mathrm{XRF}$ ) mapping, and discuss how this work, combined with an earlier study using neutron activation autoradiography (NAAR), helps to reveal the underlying figure with the greatest specificity to date.

Technical imaging methods, notably X-radiography, have considerably enhanced our understanding of the extent and revisionist nature of Rembrandt's output by revealing initial compositions-notably self-portraits, but occasionally history subjects as well. ${ }^{1}$ In 1968 , the hidden image beneath An Old Man in Military Costume was first

\footnotetext{
${ }^{1}$ For Rembrandt's reused supports, sometimes referred to as palimpsests, see Corpus I, pp. 31 ff; Corpus IV, pp. 96-98.
} 

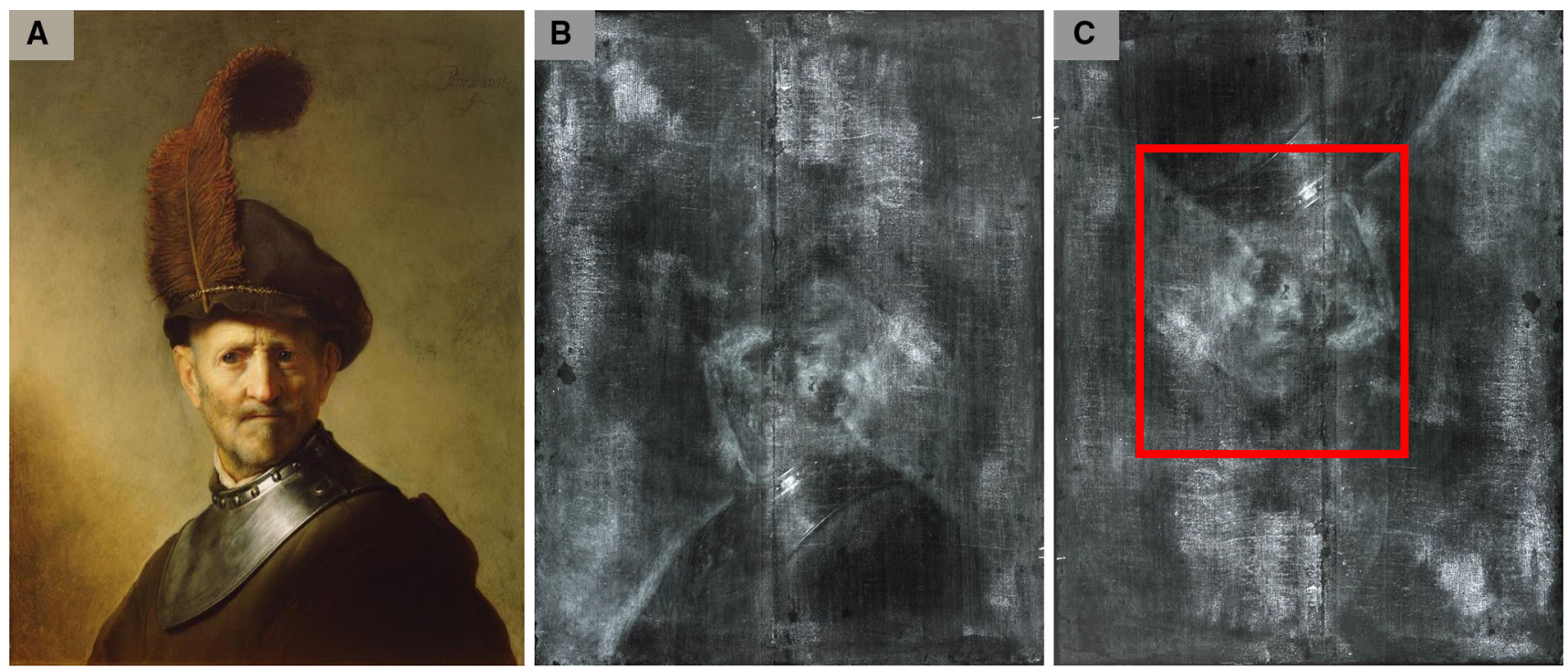

Fig. 1 a An Old Man in Military Costume by Rembrandt van Rijn (about 1630-31, oil on panel, $65.7 \times 51.8 \mathrm{~cm}$, JPGM 78.PB.246, photo credit: J. Paul Getty Museum, Los Angeles); b X-radiograph of

revealed when the painting was X-radiographed ${ }^{2}$ as part of the Rembrandt Research Project [1]. The X-radiograph, recaptured in 1978 and again in 2008 (Fig. 1b, when rotated $180^{\circ}$ Fig. $1 \mathrm{c}$ ), reveals the head of a young man in the center of the panel [2,3]. In this (inverted) orientation, the side of a man's face can be seen to the left of center, with his proper right eye, nose and lips all visible. The positioning of the upper figure over the lower is such that the major features of both faces are relatively unobscured in the X-radiograph. However, because X-radiography only measures the total density of radio-opaque material, the specific materials present in each of the layers are difficult to distinguish. While some information can be inferred, for example, whether areas were executed in a relatively higher- or lower-density material, the specific composition cannot be determined from the X-radiograph.

Since the acquisition of the painting by the J. Paul Getty Museum in 1978, a number of studies have been conducted in an attempt to better reveal and understand the underlying composition. In 1996, neutron activation autoradiography was carried out in an effort to obtain a more legible image of the underlying figure than could be provided by simple X-radiography. In NAAR [4-9], thermal neutrons are used

\footnotetext{
2 In 1968, An Old Man in Military Costume (previously titled A Man in a Gorget and a Plumed Hat) was in the collection of Sir Brian Mountain. During the 1960s, the Rembrandt Research Project had been employing technical imaging, notably X-radiography, as part of its scientific approach to the study of Rembrandt's oeuvre. Corpus I, pp. XI-XII. The finding was immediately noted by Horst Gerson and included in his Rembrandt Paintings, Amsterdam 1968, p. 490.
}

painting; c X-radiograph of painting rotated $180^{\circ}$ to better show face of underlying figure (outlined by red square)

to activate the chemical elements in the paint. Neutrons captured by the nucleus of an irradiated atom (e.g., $\left.{ }^{65} \mathrm{Cu}\right)$ convert it into a slightly heavier radioisotope $\left({ }^{66} \mathrm{Cu}\right.$ in this example). Many of the radionuclides produced in this manner will emit energetic beta particles. By placing sensitive films or image plates in close proximity to the activated painting, at specific times after the end of the activation, the distribution of one or more of the decaying radionuclides (representative of the distribution of the parent elements) can be recorded. In any given time interval, several different radionuclides will decay simultaneously, and thus the resulting images generally contain contributions from multiple elements. Nonetheless, the neutron autoradiography study of An Old Man in Military Costume provided considerable information about the underlying image, including the distribution of some key elements.

$\mathrm{X}$-ray fluorescence scanning combines elemental specificity with the ability to visualize the data as images. In this technique, a tightly focused X-ray beam is rastered over the area under investigation; the resulting fluorescent $\mathrm{X}$-rays are collected with an energy-dispersive detector to produce a full XRF spectrum at each point. Plotting the intensity of characteristic X-ray fluorescence peaks for individual elements produces a single-element distribution map. The generation of element-specific maps by means of XRF using laboratory-based instruments until recently was limited to small areas and/or to objects that could be placed in a cabinet unit [10,11]. A small area of An Old Man in Military Costume near the lips of the underlying figure was 
Table 1 Wait and exposure times for NAAR films and imaging plates

\begin{tabular}{llll}
\hline Film \# & Imaging plate set \# & Wait time after activation & Duration of exposure \\
\hline 1 & & $15 \mathrm{~m}$ & $5 \mathrm{~m}$ \\
2 & $22 \mathrm{~m}$ & $15 \mathrm{~m}$ \\
3 & $39 \mathrm{~m}$ & $35 \mathrm{~m}$ \\
4 & $1 \mathrm{~h} 17 \mathrm{~m}$ & $1 \mathrm{~h} 14 \mathrm{~m}$ \\
5 & $3 \mathrm{~h} 3 \mathrm{~m}$ & $3 \mathrm{~h}$ \\
6 & & $6 \mathrm{~h} 11 \mathrm{~m}$ & $6 \mathrm{~h}$ \\
7 & $12 \mathrm{~h} 11 \mathrm{~m}$ & $12 \mathrm{~h}$ \\
& & 1 day & $2 \mathrm{~h}$ \\
8 & 1,2 & 1 day $2 \mathrm{~h} 30 \mathrm{~m}$ & $23 \mathrm{~h} 47 \mathrm{~m}$ \\
& & 2 days $2 \mathrm{~h}$ & $5 \mathrm{~h}$ \\
9 & 3,4 & 2 days $10 \mathrm{~h}$ & $12 \mathrm{~h}$ \\
& 5,6 & 2 days $22 \mathrm{~h} 59 \mathrm{~m}$ & 3 days \\
10 & 7,8 & 5 days $23 \mathrm{~h}$ & $24 \mathrm{~h}$ \\
& & 7 days & $7 \mathrm{days}$ \\
& 9 & 8 days $9 \mathrm{~h}$ & $2 \mathrm{days} 12 \mathrm{~h}$ \\
11 & 10 & 11 days & 3 days \\
& 11 & 14 days & 14 days \\
& 12 & 28 days & 7 days \\
& & 36 days & 10 days \\
& & 78 days & 3 days \\
\hline
\end{tabular}

mapped using a Bruker Artax XRF spectrometer [12], but provided only a glimpse of the first composition. The acquisition of element maps over large areas-macro-XRF (MA-XRF) scanning-had been shown to be feasible at synchrotron radiation facilities [13-17], and the possibility of recording full-scale XRF maps of An Old Man in Military Costume using the facilities at the Stanford Synchrotron Radiation Laboratory (SSRL) was explored. A full-scale mock-up of the painting-including the underpainting — was created, and test scans were performed [18]. Although the results were promising, around this same time a mobile, macro-XRF scanner was being developed that would allow large-scale, rapid XRF scans to be performed in the gallery or museum laboratory [19, 20]. Rather than subjecting the painting to the risks associated with transporting it to a synchrotron facility, a MA-XRF scanner was brought to the Getty Center in Los Angeles to scan An Old Man in Military Costume.

This paper utilizes the results obtained by MA-XRF together with those previously obtained with neutron autoradiography to obtain the fullest understanding to date of the elemental composition of the underlying image. From these data, the pigments employed-and hence the colors - are inferred and used to produce a digital reconstruction of the underlying figure. We discuss how NAAR and MA-XRF may be used together in order to collect a substantial amount of information in a noninvasive manner on both the top and lower paintings.

\section{Experimental}

\subsection{NAAR}

In March 1996, the painting was taken to the National Institute of Standards and Technology (NIST) Center for Neutron Research (CNR) in Gaithersburg, MD, USA, where the autoradiography measurement was carried out at the Reactor Radiation Division. ${ }^{3}$ The painting was activated for $15 \mathrm{~h}$ at a thermal neutron flux of $3 \times 10^{9} \mathrm{n} /$ $\mathrm{cm}^{2}$ s. Radiation sensitive films and sets of Fuji imaging plates were placed over the surface of the painting at subsequent intervals to capture the beta radiation. The time and duration of the exposures are listed in Table 1.

NAAR images traditionally are shown as blackened films, i.e., where higher abundances of element/radionuclides correspond to darker tints. In films recorded soon after activation, fast-decaying radionuclides dominate the images while the contribution of slower-decaying ones usually is not very important, unless the corresponding element has a very high abundance. In the later films, recorded after the fast-decaying radionuclides have largely died out, the contribution of the slower-decaying radioisotopes gradually becomes more dominant. While

\footnotetext{
3 The autoradiography of the painting was coordinated by Mark Leonard, former head of Paintings Conservation at the J. Paul Getty Museum, and conducted by Henry Prask of NIST.
} 
NAAR can produce relatively clear images of the distribution of elements with sufficiently distinct decay halflives [e.g., ${ }^{56} \mathrm{Mn} \quad\left(t_{1 / 2}=2.6 \mathrm{~h}\right)$ and ${ }^{60} \mathrm{Co}\left(t_{1 / 2}-\right.$ $=1925$ days $)]$, for elements with similar emission times [e.g., ${ }_{76} \mathrm{As} \quad\left(t_{1 / 2}=24 \mathrm{~h}\right)$ and ${ }^{64} \mathrm{Cu}\left(t_{1 / 2}=12.7 \mathrm{~h}\right)$ ] the resulting images are a superposition of contributions from multiple elements, making it challenging to interpret which elements are present in the underlying painting from any single scan.

\subsection{MA-XRF}

MA-XRF maps were collected using a Bruker M6 Jetstream. This instrument consists of a measuring head that is moved over the surface of painting in a non-contact configuration by means of an XY-motorized stage. This motorized stage has a minimum step size of $10 \mu \mathrm{m}$ and a maximum travel range of $800 \times 600 \mathrm{~mm}(\mathrm{w} \times \mathrm{h})$.

The measuring head consists of an Rh-target microfocus $\mathrm{X}$-ray tube $(30 \mathrm{~W}$, maximum voltage $50 \mathrm{kV}$, maximum current $0.6 \mathrm{~mA}$ ) and a $30-\mathrm{mm}^{2}$ XFlash silicon drift detector (energy resolution $<145 \mathrm{eV}$ at $\mathrm{Mn}-\mathrm{K}_{\alpha}$ ). The beam size is defined by means of a polycapillary optic and is variable, determined by the distance between the painting and the measuring head. Two optical cameras with magnifying optics, focused on the surface of the painting at near normal angle, are mounted on the measuring head so that the area mapped can be documented.

For the Rembrandt painting An Old Man in Military Costume, element distribution maps were collected over an area measuring $660 \times 508 \mathrm{~mm}$ in a single $30 \mathrm{~h}$ session, covering nearly the complete surface of the painting; tube settings $40 \mathrm{kV}$ and $0.5 \mathrm{~mA}$, step size $650 \mu \mathrm{m}$, dwell time $90 \mathrm{~ms} / \mathrm{step}$, beam size estimated to be $350 \mu \mathrm{m}$ in diameter. All data were collected with the Bruker M6 Jetstream software package [20], and the resulting distribution maps for each element detected were exported to Photoshop ${ }^{\circledR}$ for comparison and brightness/contrast manipulation.

\section{Results}

Select NAAR images and XRF maps that reveal the most information about the hidden painting are presented below. In general, the NAAR images or MA-XRF element maps that provided information about the distribution of lead $(\mathrm{Pb})$, mercury $(\mathrm{Hg})$, copper $(\mathrm{Cu})$ and iron $(\mathrm{Fe}) /$ manganese (Mn), corresponding to the pigments lead white, vermilion, copper blues/greens and iron earths, respectively, were found to be particularly informative of the underlying figure.

\subsection{Lead}

Lead has a very small cross section for activation by thermal neutrons [5], and thus the NAAR images are unable to provide information about the distribution of this important element. However, MA-XRF easily detects $\mathrm{Pb}$ from both the $\mathrm{L}$ and $\mathrm{M}$ emission lines, and the difference in emission energies can be exploited to provide information about the distribution of this element at different depths. The $\mathrm{Pb}-\mathrm{M}_{\alpha}$ map (collected at $2.3 \mathrm{keV}$, Fig. 2a) measures only the $\mathrm{Pb}$ present in the uppermost portion of the painting, while the $\mathrm{Pb}-\mathrm{L}_{\alpha}$ distribution map (collected at $10.4 \mathrm{keV}$, Fig. 2b) reflects the presence of $\mathrm{Pb}$ both at and below the surface. Indeed, the lower image is clearly revealed by the $\mathrm{Pb}-\mathrm{L}_{\alpha}$ map: The face of the lower figure is visible just to the right of the upper head (and inverted), with the noses of the upper and lower figures lying adjacent to one another. In the area to the right and above the surface figure a cloak-like garment belonging to the figure located beneath is also visible. As with the X-radiograph, the underlying figure is more easily seen when the $\mathrm{Pb}-\mathrm{L}_{\alpha}$ map is rotated $180^{\circ}$ (Fig. 2c); to facilitate discussion of the lower figure, all subsequent images will be shown in the rotated orientation.

Due to the central role of lead white in Rembrandt's technique [21], notably as a key component in the paint used for flesh tones as well as its general use as a base for modifying the color tone of many other pigments, it is perhaps not surprising that the $\mathrm{Pb}-\mathrm{L}_{\alpha}$ map, similar to the $\mathrm{X}$-radiograph, reveals an almost complete image of the underlying figure and in particular the man's face. Notably however, the $\mathrm{Pb}-\mathrm{L}_{\alpha}$ map clearly shows a significant change that is also present, but much more difficult to see, in the $\mathrm{X}$-radiograph. There are two proper right eyes, located one over the other (see Fig. 2d); Rembrandt revised the initial position of the eye in favor of a slightly lower placement.

\subsection{Mercury}

The face of the underlying figure is most clearly revealed by the Hg-L ${ }_{\alpha}$ MA-XRF map (shown in Fig. 3a), indicative of the presence of the pigment vermilion $(\mathrm{HgS})$, which was used to tint the flesh tones of the underlying figure, and, to a lesser extent, the upper figure. Because the $\mathrm{Hg}-\mathrm{L}_{\alpha}$ map does not have a significant contribution from the surface image it reveals some features of the underlying figure even more clearly than the $\mathrm{Pb}-\mathrm{L}_{\alpha}$ map, such as the proper left eye. Along with revealing the main features of the face-including the lips, right cheek, ear, nose, jaw and chin - the $\mathrm{Hg}-\mathrm{L}_{\alpha}$ map, similar to the $\mathrm{Pb}-\mathrm{L}_{\alpha}$ map, notably shows that the eyes of the underlying head were lowered slightly after the initial execution. No indication that the 

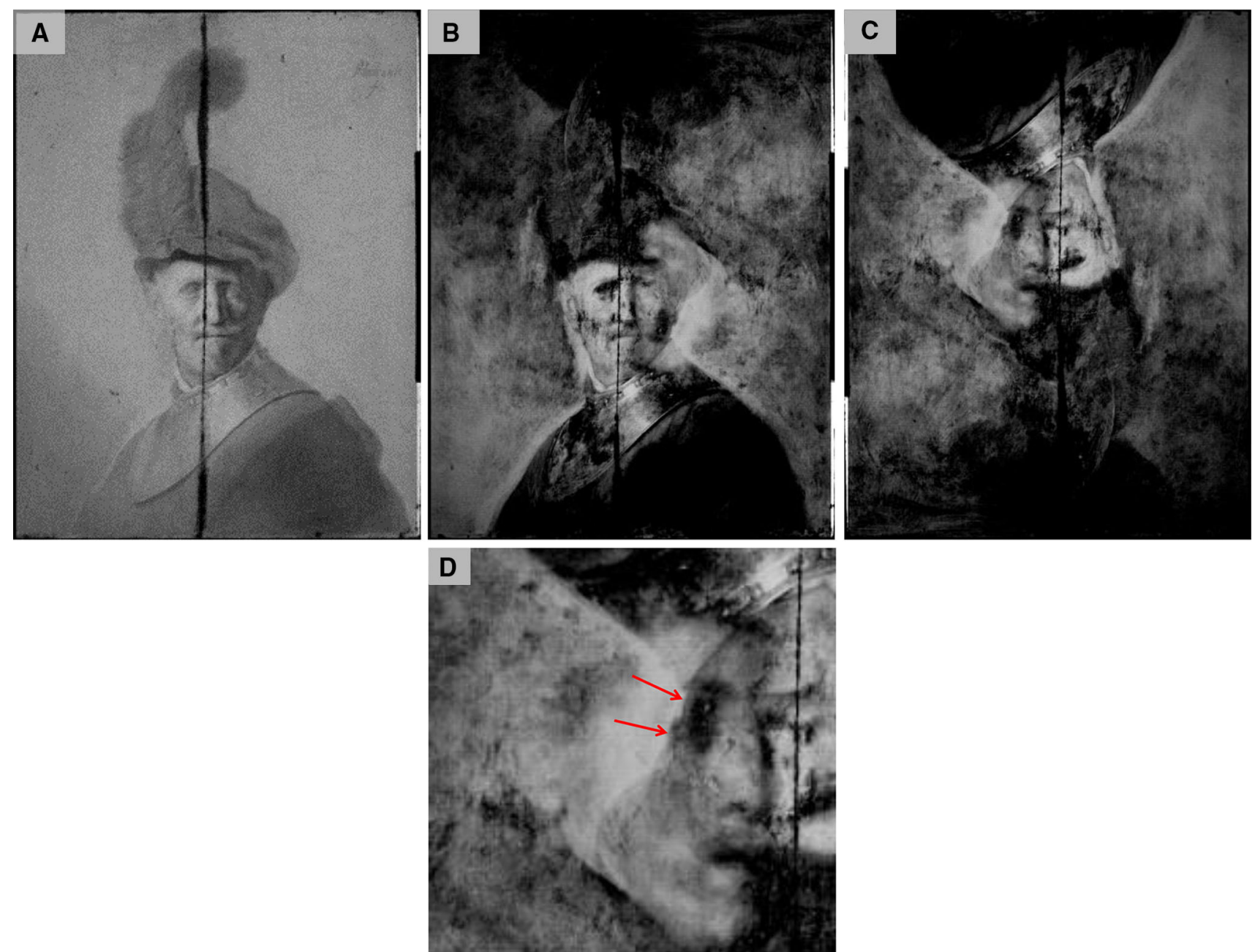

Fig. 2 a MA-XRF Pb-M $\mathrm{M}_{\alpha}$ element map; b Pb- $\mathrm{L}_{\alpha}$ element map; $\mathbf{c} \mathrm{Pb}-\mathrm{L}_{\alpha}$ element map, rotated $180^{\circ}$ to better show face and cloak of underlying man; $\mathbf{d}$ enlargement of area in $\mathbf{c}$ of face of underlying figure, with arrows pointing to the two eyes
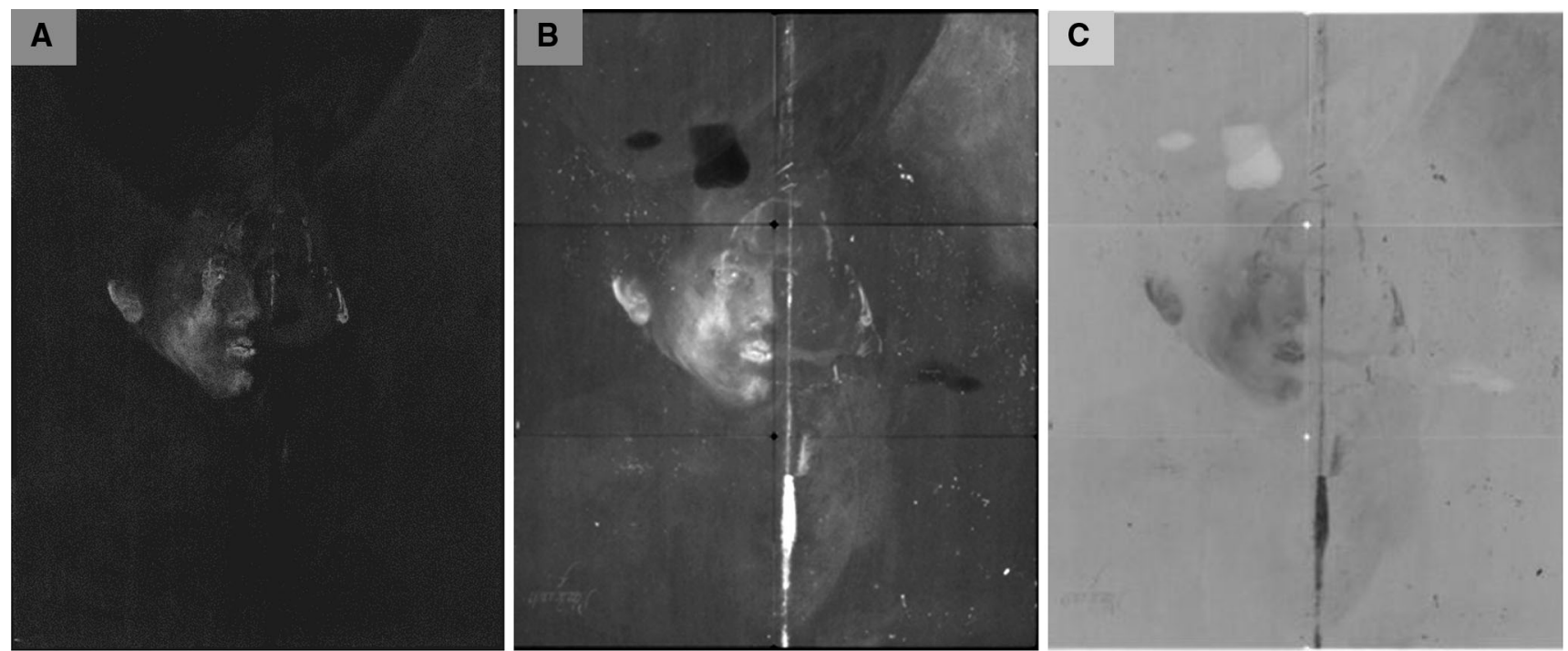

Fig. 3 a MA-XRF Hg-L $\mathrm{L}_{\alpha}$ element map; b NAAR Image Plate Set 9 (composite of six imaging plates, wait time 8 days 9 h, exposure time 2 days $12 \mathrm{~h}$ ) with gray scale inverted to facilitate comparison with MA-XRF element map; c NAAR Image Plate Set 9 (as acquired) 
position of the rest of the head of the underlying figure was adjusted is evident.

The radionuclide ${ }^{203} \mathrm{Hg}$ has a half-life of 46.6 days and is strongly activated by thermal neutrons [5]. In the NAAR images, the face of the underlying figure first becomes visible approximately 2 days following the activation, but is obscured by elements present in the upper painting. The face becomes clearer in images captured between 6 and 11 days following activation, and remains visible, with diminishing intensity, in all subsequent exposures (including the final exposure taken 78 days post-activation). The NAAR image that most clearly shows the underlying face was captured by Image Plate Set 9 (shown in Fig. 3b, c). To facilitate comparison with the MA-XRF scans, in Fig. 3b, the gray scale is inverted-with lighter values corresponding to greater exposure/nuclide concentration (all subsequent NAAR images will be similarly presented with inverted gray scales). In Fig. 3c, the NAAR image is shown as traditionally presented-as a blackened film, with darker regions corresponding to higher exposures/greater nuclide concentration. The NAAR image is dominated by $\mathrm{Hg}$ and thus, like the Hg- $\mathrm{L}_{\alpha}$ map, reveals the face of the underlying figure. However, this NAAR image also contains contributions from other elements (most notably in the area of the feather of the upper figure visible in the bottom center of Fig. 3b, c, and the background in the upper right corner), hampering straightforward interpretation of the distribution of pigments.

\subsection{Copper}

The MA-XRF map showing the distribution of $\mathrm{Cu}-\mathrm{K}_{\alpha}$ is presented in Fig. 4a. This map clearly shows that the clothing of the underlying figure and the underside of the feather in the upper figure contain significant amounts of a copper-containing pigment. A Cu-containing pigment also seems to have been used to delineate the shadows near, and edges of, the soft cap worn by the figure in the upper painting. As shown in Fig. 4b, adjusting the dynamic range of the $\mathrm{Cu}-\mathrm{K}_{\alpha}$ map to highlight the lower-intensity values (oversaturating the areas of higher $\mathrm{Cu}$ density) reveals that $\mathrm{Cu}$ is also present in the cloak of the upper figure. Figure $4 \mathrm{c}$ contains XRF spectra averaged over comparable areas of the cloak in the upper and lower figures (areas are indicated in Fig. 4b); from these, it is clear that $\mathrm{Cu}$ is indeed present in both cloaks, with a greater proportion present in the cloak of the lower figure than the upper. Comparing the peak areas of the $\mathrm{Cu}-\mathrm{K}_{\alpha}$ emission line from each spectrum gives an estimate of at least $3 \times$ greater $\mathrm{Cu}$ in the area of the cloak of the lower figure than the upper, although of course that ratio will vary depending on the areas selected. It should be noted that this abundance ratio represents a lower limit, due to absorption of $\mathrm{Cu}$ fluorescence originating from the lower cloak by the layers of paint used to obscure the hidden image and create the background of the upper painting.

Unfortunately, the identity of the copper-containing pigment cannot be determined from XRF data alone. Due
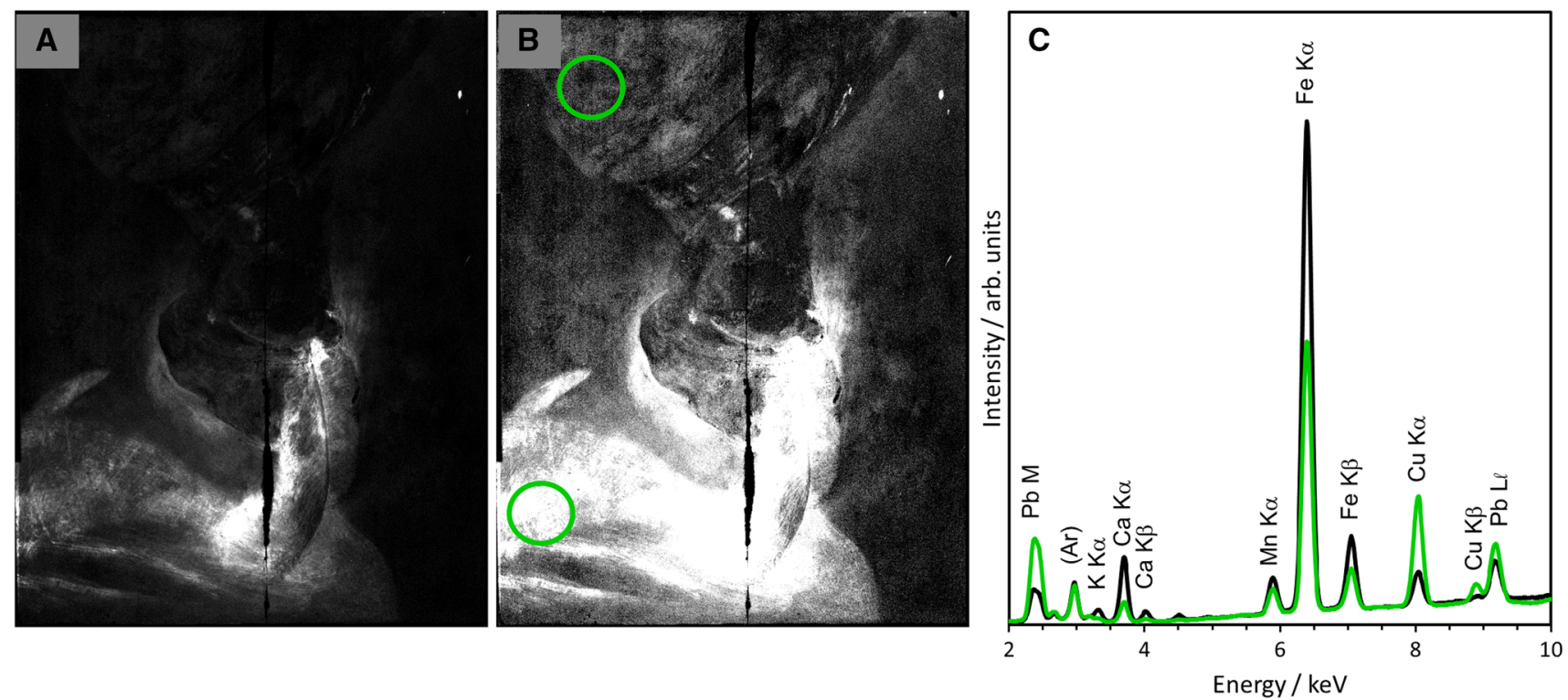

Fig. 4 a MA-XRF $\mathrm{Cu}-\mathrm{K}_{\alpha}$ element map; b map shown in a with contrast adjusted to highlight lower-intensity regions; $\mathbf{c}$ area-averaged $\mathrm{XRF}$ spectra from area of cloak in lower figure (green trace) and

upper figure (black trace). Areas over which average spectra were acquired are indicated in $\mathbf{b}$ (outlined in green) 
Fig. 5 a NAAR Film 1 (wait time $15 \mathrm{~m}$, exposure time $5 \mathrm{~m}$ ), red arrows indicate edge of contour defining proper left edge of face of underlying figure; b NAAR Film 8 (wait time $26 \mathrm{~h}$, exposure time $24 \mathrm{~h}$ ) (both films are presented with grey scales inverted)
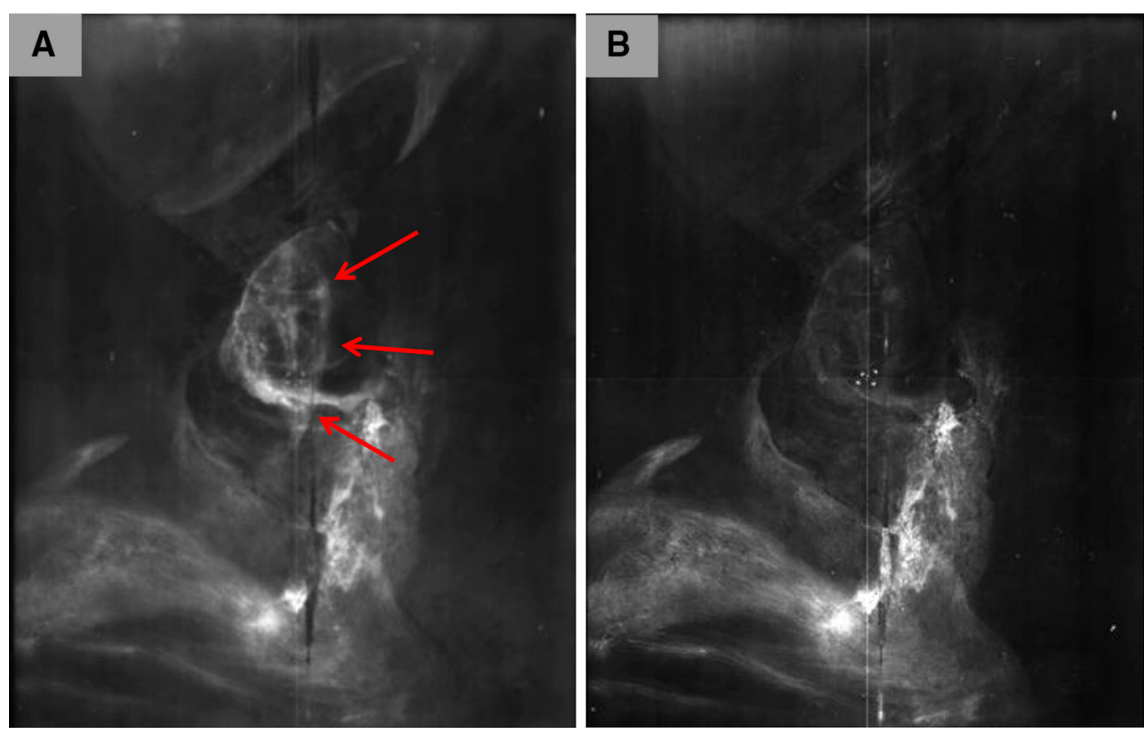

to the pristine nature of the paint surface, opportunities for sampling are extremely limited and restricted to the very edges of the painting; none of the few samples taken to date captured the $\mathrm{Cu}$-containing layer in the lower cloak. That azurite may be present throughout this area as coarsely ground particles is suggested by X-ray diffraction analysis (portable, noninvasive XRF/XRD spectrometer, InXitu Duetto [22, 23], $\mathrm{Cu} X$-ray source $\left(20^{\circ} \leq 2 \theta \leq 50^{\circ}, 0.3^{\circ}\right.$ resolution for XRD, 3-15 keV, 250-300 eV resolution for $\mathrm{XRF})$ ), which produced $\mathrm{X}$-ray diffraction rings with only a few bright spots at the spacing corresponding to the main peak of azurite. However, this does not preclude the possibility that other $\mathrm{Cu}$-containing pigments, such as copper resinate, might also be present. While it is known that Rembrandt used azurite in his early works to enliven brown tones or as a drier [21], given the circumstantial nature of this evidence, we cannot draw any conclusions from these data; additional analysis is planned to more directly probe Rembrandt's use of Cu-containing pigments in both the upper and lower compositions.

Multiple NAAR images reveal the shape of the cloak of the underlying figure: It is visible in the first exposure, taken 15 min after activation (Film 1, see Fig. 5a) and then again in all the exposures taken between 24 and $58 \mathrm{~h}$ after activation (appearing most strongly and clearly in Film 8 , exposed at $26 \mathrm{~h}$ post-activation, shown in Fig. 5b). These two time ranges, during which the shape of the coppercontaining cloak is best visualized, correspond to the maximum emission from ${ }^{66} \mathrm{Cu}$ and ${ }^{64} \mathrm{Cu}$, with half-lives of $5.12 \mathrm{~m}$ and $12.7 \mathrm{~h}$, respectively. The image in Film 8 most closely matches the $\mathrm{Cu}-\mathrm{K}_{\alpha}$ MA-XRF map, including the weaker level of emission from the cloak of the upper figure. The image in Film 1 shows a greater relative emission intensity in the region of the cloak of the upper figure, which is due to contributions from ${ }^{66} \mathrm{Cu}$ together with other elements with similarly short decay half-lives. More significantly, Film 1 contains an additional feature-the proper left edge of the face of the underlying figure. This feature is not attributable to $\mathrm{Cu}$, since it does not also appear in Film 8, nor in the $\mathrm{Cu}-\mathrm{K}_{\alpha}$ MA-XRF map. This feature therefore must be due to the presence of other elements with short decay half-lives (discussed below) that have contributed to Film 1.

\subsection{Iron/Manganese}

The proper left edge of the face of the underlying figure is visible in the NAAR image collected immediately after activation (Film 1, Fig. 5a, discussed above), is strongest in the exposures collected at 3 and $6 \mathrm{~h}$ after activation (Film 5 , collected $3 \mathrm{~h}$ post-activation, is shown in Fig. 6a, red arrows point to outline of face), and then fades in subsequent exposures. The final image in which it can be seen, very faintly, is the film collected $24 \mathrm{~h}$ after activation. There are a number of radionuclides with half-lives in this time frame, including ${ }^{56} \mathrm{Mn}(2.579 \mathrm{~h}),{ }^{31} \mathrm{Si}(2.62 \mathrm{~h}),{ }^{42} \mathrm{~K}$ $(12.36 \mathrm{~h})$ and ${ }^{24} \mathrm{Na}(14.96 \mathrm{~h})$. These elements could reasonably be present in the iron earth pigments often employed by Rembrandt. Unfortunately, no Fe distribution can be inferred from the NAAR images; during neutron activation, its most abundant isotope $\left({ }^{56} \mathrm{Fe}\right)$ is converted into another stable isotope $\left({ }^{57} \mathrm{Fe}\right)$.

While MA-XRF mapping can detect Fe, $\mathrm{Mn}$, and, to a lesser extent, $\mathrm{K}$, in the air-path configuration employed here, it cannot detect $\mathrm{Si}$ and $\mathrm{Na}$. The Fe-K $\mathrm{K}_{\alpha} \mathrm{MA}-\mathrm{XRF}$ map is presented in Fig. $6 \mathrm{~b}$ (the $\mathrm{Mn}-\mathrm{K}_{\alpha}$ map, not shown, shows the same features as the Fe map, but with lower intensities). A slight indication of the proper left edge of the underlying 

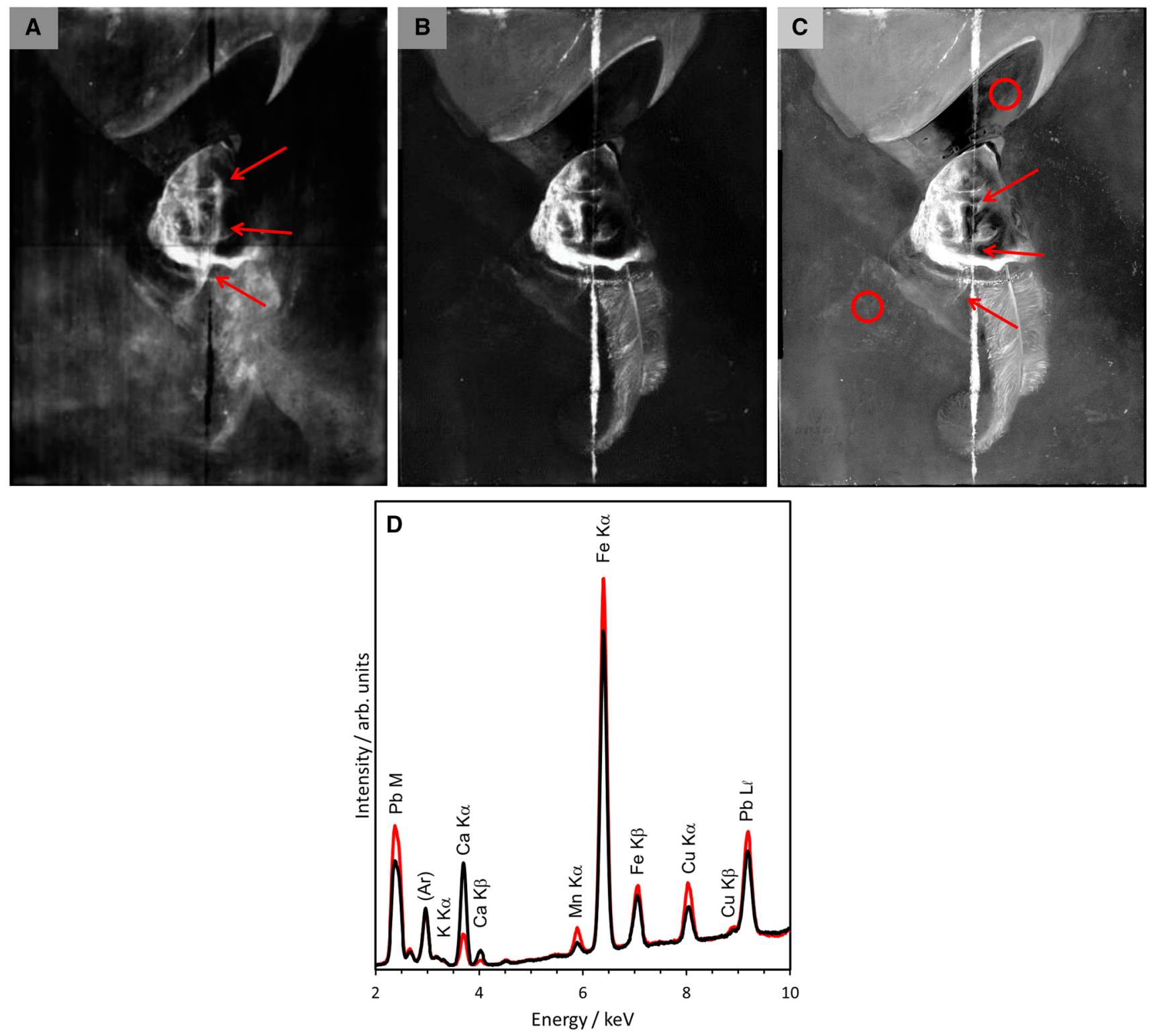

Fig. 6 a NAAR Film 5 (wait time 3 h, exposure time 3 h), red arrow indicates edge of contour defining proper left edge of face of underlying figure; $\mathbf{b} \mathrm{MA}-\mathrm{XRF} \mathrm{Fe}-\mathrm{K}_{\alpha}$ element map; $\mathbf{c} \mathrm{MA}-\mathrm{XRF} \mathrm{Fe}-\mathrm{K}_{\alpha}$ element map adjusted to better show gorget/collar of hidden man;

face can be seen in the $\mathrm{Fe}-\mathrm{K}_{\alpha}$ map (this feature is more visible with adjustment of the brightness/contrast of the image, shown in Fig. 6c), but not as clearly as in the NAAR image (Fig. 6a). That the left side of the face of the underlying figure is not readily apparent in any of the XRF maps collected suggests it may be due to an element with limited or reduced fluorescence intensity-either something that is effectively absorbed by an overlying layer, or consisting of lower $\mathrm{Z}$ elements. The strong correlation between the $\mathrm{Fe}-\mathrm{K}_{\alpha}$ and $\mathrm{Mn}-\mathrm{K}_{\alpha}$ distribution maps suggests Rembrandt used iron earth pigments in the form of umbers (alumina-silicate earth pigments colored by iron oxides d area-averaged XRF spectra from area of gorget/collar in lower figure (red trace) and upper figure (black trace). Areas over which average spectra were acquired are indicated in $\mathbf{c}$ (outlined in red)

$\mathrm{Fe}_{2} \mathrm{O}_{3}$ and $\mathrm{FeOOH}$, with umbers also containing $\mathrm{MnO}_{2}$ ) $[24,25]$. Taken together, the complementary information provided by the NAAR and MA-XRF data suggests that this portion of the face of the underlying figure was executed in an iron earth pigment-specifically, an umberfor which the Fe and Mn content is visualized in the MAXRF maps, and the Si content is visualized in the NAAR image.

The $\mathrm{Fe}-\mathrm{K}_{\alpha} \mathrm{XRF}$ map also provides additional insight into the shape of the garment of the underlying figure. The Fe- $\mathrm{K}_{\alpha}$ map, in particular, shows a shape consistent with either a metal gorget, similar to that worn by the upper figure, or a fur collar 


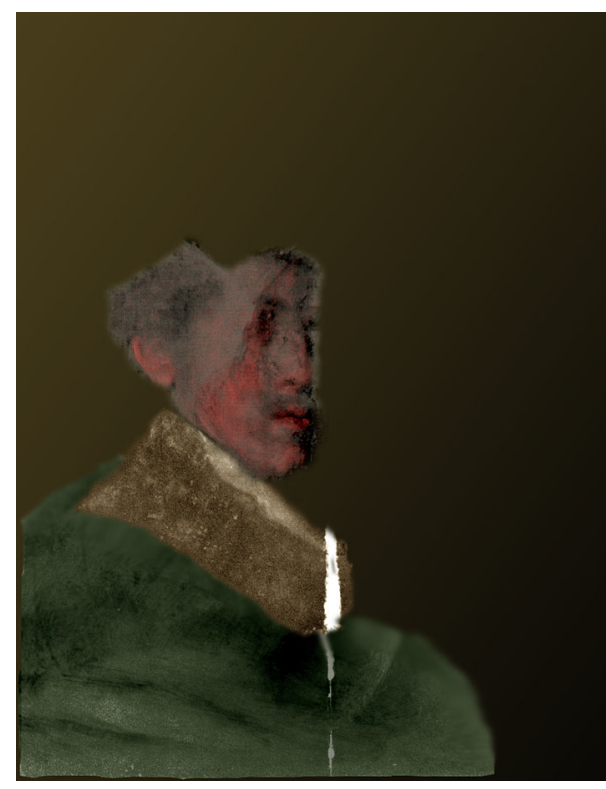

Fig. 7 Tentative color reconstruction of underlying figure

worn over a tunic. Upon adjusting the brightness/contrast to highlight this portion of the image (see Fig. 6c), it appears that this area is not homogeneous, but rather has a somewhat "spotty" appearance, which might be more consistent with a fur collar than a metal gorget. Area-averaged XRF spectra from regions of the collar/gorget in the upper and lower figures are shown in Fig. 6d (given the variation in light and shadow on the upper gorget, the areas were selected to represent regions considered to have similar levels of illumination). Overall, the two spectra do not show significant differences. A higher Ca signal is observed in the spectrum from the area of the gorget in the upper figure but, because of its shorter X-ray fluorescence escape depth (higher likelihood of having been absorbed by the upper paint layers), this does not preclude this element also being present in the lower gorget/collar area. Slightly higher levels of $\mathrm{Mn}, \mathrm{Fe}$ and $\mathrm{Cu}$ are observed in the spectrum from the area over the lower gorget/collar area, but whether these elements represent a greater concentration of iron earth pigment in the lower gorget/collar, or in the paint layers used to obscure the underlying composition, cannot be determined from these data.

\section{Reconstruction of underlying figure}

In Fig. 7, a tentative color reconstruction of the underlying figure is presented. ${ }^{4}$ This reconstruction combines relevant parts of the MA-XRF distributions of the elements $\mathrm{Cu}, \mathrm{Fe}$,

\footnotetext{
${ }^{4}$ A preliminary discussion of initial findings was presented at the conference New Directions in the Study of Rembrandt and His Circle, held at Queen's University, Bader International Study Centre, Herstmonceux Castle, East Sussex, UK, July 18-21, 2013.
}

$\mathrm{Hg}$ and $\mathrm{Pb}$ that could be identified, on the basis of X-radiography, NAAR and/or MA-XRF mapping, as belonging to the three main components of the lower figure-the cloak, the collar/gorget and the face/head. Each component was given a color corresponding to that of pigments inferred to be present based on the detected elements, combined with visual observation and comparison with other paintings by Rembrandt; minimal use of image processing tools was employed. The skin tones were colored a range of pink tonalities; the collar/gorget was colored an off-white, grayish tone, and the cloak was colored a brown/olive green. Note that some areas in the reconstruction show the shielding effect of features in the surface picture. This is particularly evident in the diagonal line through the face, caused by the strong contour line of the beret in the upper figure. The area inside the dark beret, composed of light elements, is more transparent to $\mathrm{X}$-rays, while the lighter, $\mathrm{Pb}$-rich background effectively attenuates the XRF signal of lower layers. Other parts of the composition could not be reconstructed and were therefore given a neutral dark brown background.

\subsection{Cloak}

Both the NAAR images as well as the $\mathrm{Cu}-\mathrm{K}_{\alpha} \mathrm{MA}-\mathrm{XRF}$ map clearly reveal the broad brush strokes used to paint the cloak. It is also clear that near the upper part of the cloak, below the neck of the figure, an area was left in reserve for a gorget or collar. Rembrandt painted many figures in which men wear either a gorget or collar on top of a tunic or equivalent garment. The outline of the cloak worn by the lower figure, visible in the NAAR films best visualizing the distribution of $\mathrm{Cu}$ (see Fig. 5), was used to identify the relevant area in the MA-XRF $\mathrm{Cu}-\mathrm{K}_{\alpha}$ map; the rest of the $\mathrm{Cu}-\mathrm{K}_{\alpha}$ map was masked out. Also, the high $\mathrm{Cu}$ intensity in the area of the underside of the feather plume in the upper figure was toned down to match the level of $\mathrm{Cu}$ in the hidden cloak in an effort to remove the contribution from the upper painting. Since the hidden cloak has, on average, a minimum of $3 \times$ higher $\mathrm{Cu}$ intensity than in the cloak of the upper figure we consider it plausible that the overpainted tunic/cloak has a significantly more blue-green tonality (stemming from the use of, e.g., blue azurite and/or another green copper-containing pigment) than the one now visible as part of the upper painting. However, the precise color cannot be determined directly from these data. Rembrandt only very rarely employed blue as a color for garments; instead brown/olive green tones prevail, and therefore we employ such a tone for this reconstruction.

\subsection{Gorget/collar}

In the MA-XRF Fe- $\mathrm{K}_{\alpha}$ map, an area of intensity having the same shape as the reserve area in the $\mathrm{Cu}-\mathrm{K}_{\alpha}$ map is visible, 
which appears to correspond to a gorget/collar on the underlying figure. As discussed above, area-averaged XRF spectra from the gorget/collar areas in the upper and lower images considered to have comparable levels of illumination were very similar. We assume that both gorget/collar areas were painted with a similar palette, and thus a warm gray false color was assigned to this area in the lower composition. It is intriguing to note that part of the cloak appears to continue behind/on top of the gorget on the left side of the image suggesting that, very similar to the upper figure the hidden man also wore an outer layer of clothing above his tunic [which likewise contained copper-containing pigment(s)]. When considering the overall shape of the cloak and the gorget/collar of the lower figure, we can conclude that there is a great similarity with the upper figure.

\subsection{Head}

The concealed figure is turned, with his right shoulder toward the viewer. The proper right contour of the hidden face is well defined by the MA-XRF $\mathrm{Hg}-\mathrm{L}_{\alpha}$ map (Fig. 3a) as well as the NAAR image (Fig. 3c). The higher intensity of $\mathrm{Pb}$ and $\mathrm{Hg}$ on the proper right side of his face indicates the light is falling across his right shoulder; the left side of his face is in shadow, the outline of which is best visualized by the NAAR image shown in Fig. 6a, which suggests the use of Si-containing $\mathrm{Fe}$ earth pigments in this area. A fairly thin face emerges, perhaps of the same type as that seen in the upper image. The distribution of $\mathrm{Pb}$ (as white) and $\mathrm{Hg}$ (as red) was combined to produce a range of pink tonalities for the subject's face.

Unfortunately, none of the X-radiograph, NAAR or MA-XRF images provide any indication of the upper part of the hidden figure's head or headdress. While Rembrandt very often (but not always) paints himself and others wearing different types of headdresses, it is not possible to infer anything from the available technical images on this aspect of the painting.

\section{Conclusions}

Rembrandt's use of a limited palette can create challenges for their chemical analysis, as it can be difficult to capture subtle changes across a composition, or, in this case, between two overlying paintings, with point analyses. However, as we have shown, the use of the elementspecific imaging techniques NAAR and MA-XRF, together with X-radiography, has allowed us to visualize the image that lies hidden below the surface of An Old Man in Military Costume by Rembrandt.
While NAAR images tend to be more difficult to interpret because they usually contain contributions from more than one element, and hence more than one pigment, XRF maps provide information on the distribution of pigments more directly and intuitively. The different mechanism by which the images are created also effects the sharpness of the resulting image. In NAAR, both copper and mercury radionuclides produce high-energy radiation, to which the film is exposed well beyond the local point of contact between the paint and film, which can cause blurring in the NAAR images. By contrast, the beam-based MA-XRF images are much sharper. However, the absorption of characteristic X-ray fluorescence radiation emitted by elements in underlying paint layers by overlying strata may significantly influence the maps. Thus, XRF mapping is a good complement to more traditional techniques, but does not supplant them: MAXRF provides another tool that allows researchers to contribute to the ever-growing knowledge about works of art.

The challenge of reconstructing the overpainted figure in An Old Man in Military Costume was significantly advanced by the judicious combined use of imaging methods. The X-radiograph image provided information on part of the face and the area of the eyes since it largely reflects the distribution of lead white. The $\mathrm{Hg}$ and $\mathrm{Cu}$ MAXRF maps (and their NAAR counterparts) allowed the reconstruction of other parts of the face and the cloak/tunic of the figure, while the MA-XRF Fe distribution revealed the shape of his gorget or collar. Although additional aspects of the hidden painting remain elusive-in particular, the treatment of the hair/headdress - this new reconstruction, and associated information on the pigments employed in both the upper and lower images serves to invigorate the art-historical discussion on the exact nature of the concealed figure and its significance in Rembrandt's oeuvre.

Acknowledgments The authors gratefully acknowledge the assistance of all those who aided in the examination of this painting over the decades, that has culminated in the work presented here. Particular thanks go to Mark Leonard (former head of Paintings Conservation at the J. Paul Getty Museum) and Henry Prask (NIST) for carrying out the NAAR analysis; John Twilley (former GCI Scientist) for early investigations; Andrea Sartorius (former JPGM Paintings intern) for creating a mock-up painting used in earlier phases of this work; Peter Reishig (former GCI intern) for compiling the NAAR data; Catherine Patterson, Lynn Lee, and David Carson (GCI Science) and Gene Karraker (JPGM Paintings Conservation) for helping with the setup and operation of the M6 Jetstream; and Giacomo Chiari (former head of GCI Science) for performing the XRD analysis. Koen Janssens and Geert van der Snickt acknowledge the Fund Inbev-Baillet Latour for financial support. Joris Dik acknowledges the help of the Netherlands Organization for Scientific Research (NWO) in the form of a VIDI grant in the Innovational Research Incentive Scheme. 
Open Access This article is distributed under the terms of the Creative Commons Attribution 4.0 International License (http://crea tivecommons.org/licenses/by/4.0/), which permits unrestricted use, distribution, and reproduction in any medium, provided you give appropriate credit to the original author(s) and the source, provide a link to the Creative Commons license, and indicate if changes were made.

\section{References}

1. E. Van de Wetering, A Corpus of Rembrandt Paintings IV: SelfPortraits (Springer, New York, 2006)

2. W. Leidtke, Burlingt. Mag. 137, 458-462 (1995)

3. A.T. Woollett, R.H. van Rijn, Rembrandt in Southern California (J. Paul Getty Museum, Los Angeles, 2009)

4. M.W. Ainsworth, Art and Autoradiography: Insights into the Genesis of Paintings by Rembrandt, Van Dyck, and Vermeer (Metropolitan Museum of Art, New York, 1982)

5. E.V. Sayre, H.N. Lechtman, Stud. Conserv. 13, 161-185 (1968)

6. C.O. Fischer, M. Gallagher, C. Laurenze, C. Schmidt, K. Slusallek, Nuclear instruments and methods in physics research section A: accelerators. Spectrom. Detect. Assoc. Equip. 424, 258-262 (1999)

7. A. Denker, K. Kleinert, C. Laurenze-Landsberg, M. Reimelt, B. Schröder-Smeibidl, Nuclear instruments and methods in physics research section A: accelerators. Spectrom. Detect. Assoc. Equip. 651, 273-276 (2011)

8. A. Kalicki, E. Panczyk, L. Rowinska, B. Sartowska, L. Walis, K. Pytel, B. Pytel, A. Koziel, L. Dabkowski, M. Wierzchnicka, L. Strzalkowski, T. Ostrowski, Radiat. Meas. 34, 567-569 (2001)

9. P. Meyers, M.W. Ainsworth, J. Brealey, M.J. Cotter, E. Haverkamp-Begemann, E.V. Sayre, L. van Zelst, Stud. Conserv. 27, 165-168 (1982)

10. D.A. Scott, Archaeometry 43, 475-482 (2001)
11. H. Bronk, S. Röhrs, A. Bjeoymikhov, N. Langhoff, J. Schmalz, R. Wedell, H.-E. Gorny, A. Herold, U. Waldschläger, Fresenius J. Anal. Chem. 371, 307-316 (2001)

12. K. Trentelman, M. Bouchard, M. Ganio, C. Namowicz, C.S. Patterson, M. Walton, X-Ray Spectrom. 39, 159-166 (2010)

13. K. Janssens, J. Dik, M. Cotte, J. Susini, Acc. Chem. Res. 43, 814-825 (2010)

14. D.L. Howard, M.D. de Jonge, D. Lau, D. Hay, M. Varcoe-Cocks, C.G. Ryan, R. Kirkham, G. Moorhead, D. Paterson, D. Thurrowgood, Anal. Chem. 84, 3278-3286 (2012)

15. A.R. Woll, J. Mass, C. Bisulca, R. Huang, D.H. Bilderback, S. Gruner, N. Gao, Appl. Phys. A 83, 235-238 (2006)

16. K. Janssens, G. Vittiglio, I. Deraedt, A. Aerts, B. Vekemans, L. Vincze, F. Wei, I. Deryck, O. Schalm, F. Adams, A. Rindby, A. Knöchel, A. Simionovici, A. Snigirev, X-Ray Spectrom. 29, 73-91 (2000)

17. J. Dik, K. Janssens, G. Van Der Snickt, L. van der Loeff, K. Rickers, M. Cotte, Anal. Chem. 80, 6436 (2008)

18. M. Alfeld, W. De Nolf, S. Cagno, K. Appel, D.P. Siddons, A. Kuczewski, K. Janssens, J. Dik, K. Trentelman, M. Walton, A. Sartorius, J. Anal. At. Spectrom. 28, 40-51 (2013)

19. M. Alfeld, K. Janssens, J. Dik, W. de Nolf, G. van der Snickt, J. Anal. At. Spectrom. 26, 899 (2011)

20. M. Alfeld, J.V. Pedroso, M. van Eikema, G. Hommes, G. Van der Snickt, G. Tauber, J. Blaas, M. Haschke, K. Erler, J. Dik, K. Janssens, J. Anal. At. Spectrom. 28, 760 (2013)

21. D. Bomford, Art in the Making (Yale University Press, Rembrandt, 2006)

22. G. Chiari, Nature 453, 159 (2008)

23. P. Sarrazin, G. Chairi, M. Gailhanou, Adv. X-Ray Anal. 52, 1186-1757 (2009)

24. R.J. Gettens, G.L. Stout, Painting Materials: A Short Encyclopedia (Dover, New York, 1966)

25. D. Hradil, T. Grygar, J. Hradilová, P. Bezdička, Appl. Clay Sci. 22, 223-236 (2003) 